Published in "Gene Expression Patterns 30: 49-54, 2018"

which should be cited to refer to this work.

\title{
Expression pattern of delta-like 1 homolog in developing sympathetic neurons and chromaffin cells
}

\author{
Tehani El Faitwri ${ }^{\mathrm{a}, \mathrm{b}}$, Katrin Huber ${ }^{\mathrm{a}, \mathrm{c}, *}$ \\ a Institute of Anatomy \& Cell Biology, Albert-Ludwigs-University Freiburg, Albert-Str. 17, 79104, Freiburg, Germany \\ ${ }^{\mathrm{b}}$ Department of Histology and Anatomy, Faculty of Medicine, Benghazi University, Benghazi, Libya \\ ${ }^{\mathrm{c}}$ Department of Medicine, University of Fribourg, Route Albert-Gockel 1, 1700, Fribourg, Switzerland
}

Keywords:

Sympathetic neurons

Chromaffin cells

DLK1

Adrenal gland

Organ of Zuckerkandl

Development

Neural crest

Phox2B

\begin{abstract}
A B S T R A C T
Delta-like 1 homolog (DLK1) is a member of the epidermal growth factor (EGF)-like family and an atypical notch ligand that is widely expressed during early mammalian development with putative functions in the regulation of cell differentiation and proliferation. During later stages of development, DLK1 is downregulated and becomes increasingly restricted to specific cell types, including several types of endocrine cells. DLK1 has been linked to various tumors and associated with tumor stem cell features. Sympathoadrenal precursors are neural crest derived cells that give rise to either sympathetic neurons of the autonomic nervous system or the endocrine chromaffin cells located in the adrenal medulla or extraadrenal positions. As these cells are the putative cellular origin of neuroblastoma, one of the most common malignant tumors in early childhood, their molecular characterization is of high clinical importance. In this study we have examined the precise spatiotemporal expression of DLK1 in developing sympathoadrenal cells. We show that DLK1 mRNA is highly expressed in early sympathetic neuron progenitors and that its expression depends on the presence of Phox2B. DLK1 expression becomes quickly restricted to a small subpopulation of cells in sympathetic ganglia, while virtually all chromaffin cells in the adrenal medulla and the Organ of Zuckerkandl still express high levels of DLK1 at late gestational stages.
\end{abstract}

\section{Introduction}

Sympathetic neurons of the autonomic nervous system and the endocrine chromaffin cells are neural crest derived cells that share many characteristics, including the expression of the catecholaminergic pathway enzymes tyrosine-hydroxylase (TH) and dopamin- $\beta$-hydroxylase (DBH). The later constitute the adrenal medulla and release catecholamines into the blood stream in response to stimulation by preganglionic sympathetic nerve fibers. During development chromaffin cells are also located in extra-adrenal positions, such as the organ of Zuckerkandl (OZ), which is believed to be the major source of catecholamines during fetal life (West et al., 1953). In mouse embryos it is located on the anterior surface of the aorta at the level of the renal pelvis and can be identified by the presence of TH-immunofluorescence and the absence of neurofilament (NF) expression (Schober et al., 2013). Originally, it was postulated that sympathetic neurons and chromaffin cells originate from a common bipotential sympathoadrenal precursor (Anderson and Axel, 1986), but Furlan and colleagues reported recently that at least a major subpopulation of chromaffin cells develops indirectly from neural crest cells via Schwann cell precursors
(Furlan et al., 2017). However, due to the strong similarities between the precursors of sympathetic neurons and chromaffin cells with regard to their molecular profile and developmental transcription factor dependence (Huber, 2006, 2015) the term "sympathoadrenal (SA)" is still used here. The development of SA cells is governed by a transregulatory transcription factor network (Chan et al., 2018; Huber, 2006), which among others comprises the homeodomain transcription factor Phox2B (Huber et al., 2005; Pattyn et al., 1999) and the basic helix loop helix transcription factors Mash1 (Huber et al., 2002; Pattyn et al., 2006). A precise knowledge of the molecular players and pathways that operate during SA development is of high significance in a clinical context, as these precursor cells are the cellular origin of neuroblastoma, a malignant early childhood tumor derived from embryonic tissue (for a recent review see Tsubota and Kadomatsu, 2018).

Delta Like-1 homolog (DLK1), also known as preadipocyte factor 1 (Pref-1) and pG2 (Lee et al., 1995), is a paternally imprinted gene located on human chromosome 14q32 (Gubina et al., 1999) and mouse chromosome 12 (Gubina et al., 2000). It encodes a transmembrane epidermal growth factor (EGF)-like protein containing six tandem EGFlike repeats (Smas and Sul, 1993; Smas et al., 1994). DLK1 is a non-

\footnotetext{
* Corresponding author. Department of Medicine, University of Fribourg, Route Albert-Gockel 1, 1700, Fribourg, Switzerland.

E-mail address: katrin.huber@unifr.ch (K. Huber).
} 

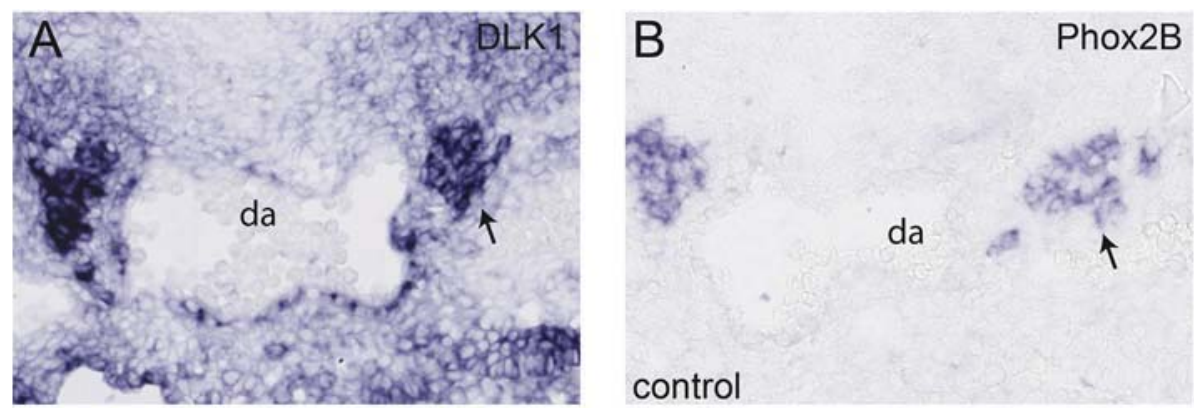

Fig. 1. (A) DLK1 is expressed at high levels in primary sympathetic ganglia (arrows) of E10.5 control mouse embryos. (C) In Phox $2 \mathrm{~B}^{\mathrm{LacZ} / \mathrm{LacZ}}$ mice the strong signal at the sites of primary sympathetic ganglia is lacking. Photomicrographs show cross sections through thoracic sympathetic ganglia (arrows) of E10.5 (A,B) control and (C,D) Phox $2 \mathrm{~B}^{\mathrm{LacZ} /}$ LacZ mouse embryos. In-situ-hybridizations for $(A, C)$ DLK1, (B) Phox2B and (D) LacZ were performed in near adjacent sections. (da) dorsal aorta. Bar: $50 \mu \mathrm{m}$.
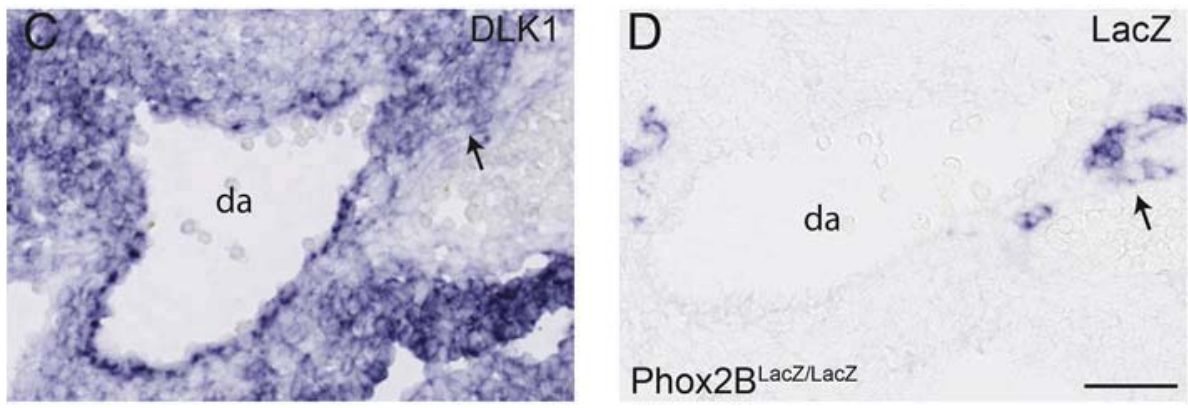

canonical notch ligand interacting with the Delta-Notch signaling pathway, which is involved in cell fate decisions, progenitor maintenance and cell differentiation (Bray, 2006; Fiúza and Arias, 2007; D'Souza et al., 2010). DLK1 is widely expressed during embryonic development of mammals (Falix et al., 2013), but in the adult its expression is downregulated and highly restricted to certain organs, including adrenal chromaffin cells (Jensen et al., 1993; Larsen et al., 1996; Hedlund et al., 2003). Despite its widespread expression during embryonic development, mice carrying deletions of DLK1 display relatively mild deficits, including a partially penetrant neonatal lethality, growth retardation, skeletal deficits and accelerated adiposity (Moon et al., 2002; Appelbe et al., 2013). Yet, the functions of DLK1 are only partially understood (Appelbe et al., 2013).

DLK1 has also been linked to tumor biology and associated with cancer stem-cell features (Yin et al., 2006; Kim et al., 2009; Xu et al., 2012; Cai et al., 2016). Its expression has been detected in a variety of tumor cells, including certain types of neuroblastoma cells (van Limpt et al., 2003; Kim et al., 2009; Begum et al., 2012). Here we report the spatiotemporal expression pattern of DLK1 in sympathoadrenal cells in the course of their development to link the normal molecular properties of these cells to their tumor biology.

\section{Materials and methods}

\subsection{Experimental animals}

Phox2B ${ }^{\text {Lacz }}$ mice (Pattyn et al., 1999) were described previously. Pregnant C57BL/6J or Phox $2 \mathrm{~B}^{\mathrm{Lacz}}$ mice were sacrificed by cervical dislocation and embryos were removed at embryonic day (E)10.5, E11.5, E13.5 or E18.5. The day of vaginal plug identification was designated E0.5. The study was carried out in strict accordance with the German Federal Animal Welfare Law and care of animals was in accordance with institutional guidelines.

\subsection{Histology}

Embryos were fixed in $4 \%$ paraformaldehyde (PFA) overnight Tissues were then rinsed 3 times with PBS and transferred into 30\% sucrose in PBS for cryoprotection. After immersion in sucrose overnight the tissue was coated with $\mathrm{OCT}^{\mathrm{TM}}$ compound (Tissue Tek), frozen on dry ice, and stored at $-80{ }^{\circ} \mathrm{C}$ until further processing. Tissues were then cut into $10 \mu \mathrm{m}$ serial sections, mounted on Superfrost ${ }^{\mathrm{TM}}$ slides, and air dried for $30 \mathrm{~min}$, before performing in situ hybridization or immunocytochemistry as indicated below.

\subsection{Immunohistochemistry}

For immunohistochemistry, slides were pretreated with 3\% hydrogen peroxide in PBS for $15 \mathrm{~min}$. After incubation with sheep polyclonal anti-TH (1:500; AB1542, Merck-Millipore, Darmstadt, Germany) or rabbit anti-Phox2B (1:400; kindly provided by Dr. Christio Goridis, 'École Normale Supérieure, Inserm, Paris, France) diluted in PBS, sections were incubated with the appropriate biotinylated secondary antibody, rinsed with PBS and incubated for $1 \mathrm{~h}$ with avidin and biotinylated horseradish-peroxidase-macromolecular complex (Vector: Elite $A B C$ reagent) according to the manufacturer's instructions. Sections were then rinsed with PBS and stained with 3-amino-9-ethylcarbazol (Sigma; red staining) according to the manufacturer's instructions. After being rinsed with PBS, sections were mounted with Kaiser's glycerol gelatine (Merck).

\subsection{In situ hybridization}

In situ hybridization (ISH) on cryosections and preparation of digoxigenin-labelled riboprobes for mouse Phox2B (Pattyn et al., 1997), SF-1 (Gut et al., 2005), neurofilament (NF) 68 (Huber et al., 2002), and LacZ (Huber et al., 2005) were carried out by using a modification of the protocol of D. Henrique (IRFDBU, Oxford, UK) as previously described (Ernsberger et al., 1997). Mouse DLK1 (gene bank accession number: NM 010052 number; 236bp -741 bp) was cloned by RT-PCR using a pGEM-T vector system (Promega) following the manufacturer's instructions. The plasmids were linearized with SacII and transcribed with SP6. The specificity of the probes was tested using appropriate sense controls. If required, immunohistochemistry was carried out following in situ hybridization.

\section{Results}

We investigated the expression of DLK1 by in-situ-hybridization in the area of sympathetic ganglia, the adrenal gland, and the $\mathrm{OZ}$ in mouse embryos of different developmental stages starting at E10.5. At this age DLK1 is expressed in a variety of tissues and particular strong signals 

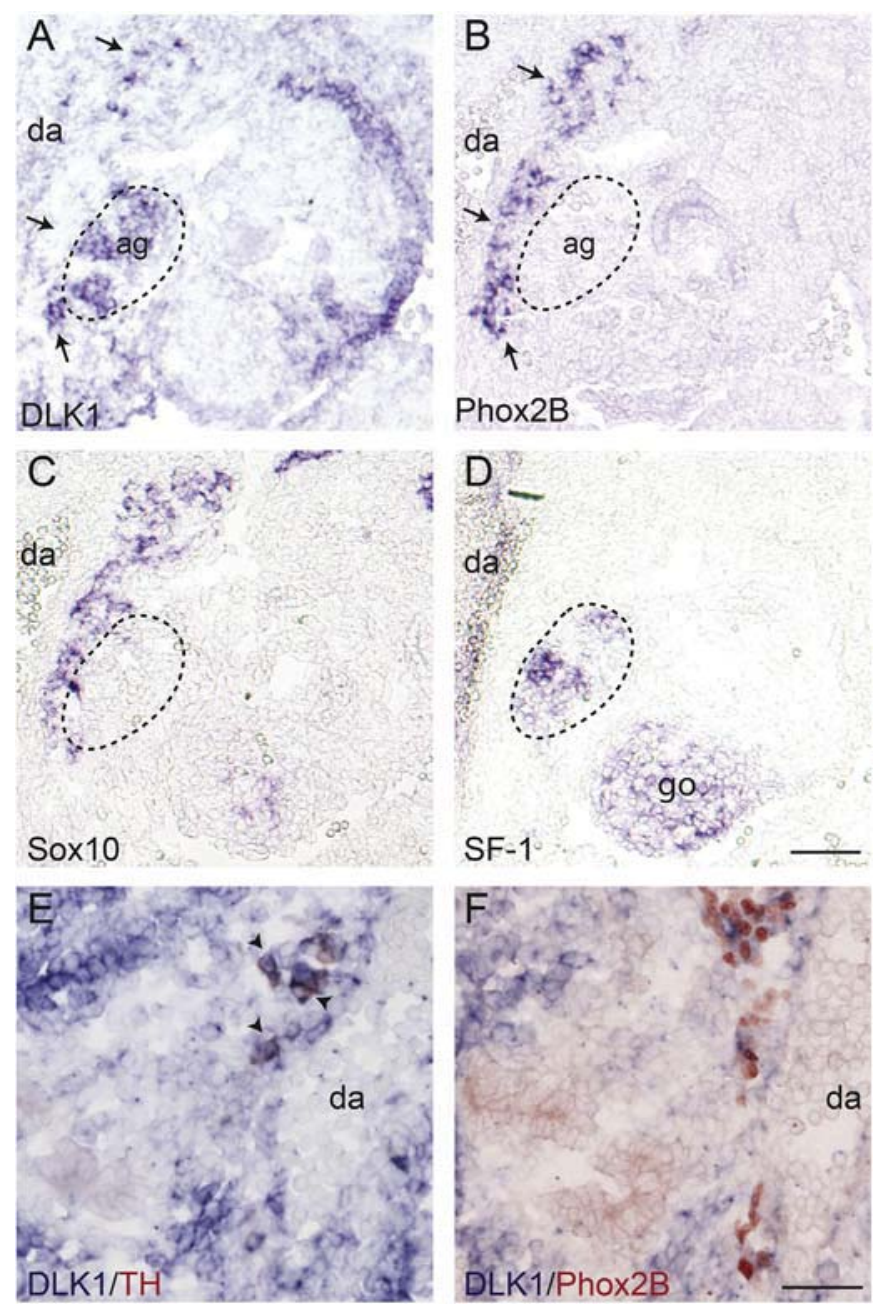

Fig. 2. DLK1 is expressed at the site of the developing adrenal cortex. Cross sections through E10.5 mouse embryos at the level of the developing adrenal gland. In-situ-hybridizations for (A) DLK1, (B) Phox2B, (C) Sox10 and (D) SF-1, a marker for the developing adrenal cortex, were performed in near adjacent sections. Note that in the area of Phox2B and Sox10 expression only few cells appear positive for DLK1 (arrows). (E,F) In-situ-Hybridizations for DLK1 (blue) followed by immunostainings for TH (E: red cytoplasmatic stain) and Phox2B (F: red nuclear stain). Note that all TH immunoreactive cells (arrowheads) are positive for DLK1, while only some of Phox2B immunoreactive cells co-express DLK1. (ag) adrenal gland; (da) dorsal aorta; (go) gonad. Bars: A-D: $100 \mu \mathrm{m}$; E,F: $50 \mu \mathrm{m}$. were observed in the developing liver and at the sites of the primary sympathetic ganglia adjacent to the dorsal aorta (Fig. 1A). To identify the position of the primary sympathetic ganglia, a near adjacent section was labelled using a probe for Phox2B (Fig. 1B). DLK1-ISH combined with TH-immunostaining revealed that virtually all TH-positive cells in the thoracic primary ganglia express DLK1 (Fig. 4A) at this developmental stage.

The differentiation of sympathoadrenal cells from neural crest cells is controlled by a complex transregulatory transcription factor network, whose activation essentially depends on the homeodomain transcription factor Phox2B (Huber et al., 2005; Pattyn et al., 1999). To investigate, whether DLK1 expression in the SA cells is downstream of Phox2B, we analyzed DLK1 expression in Phox2B deficient (Phox2B ${ }^{\text {Lacz/ }}$ Lacz) mouse embryos. As shown in Fig. 1C the strong DLK1 signal that was detected in control mice was not observed at the site of LacZ positive cells accumulating adjacent to the dorsal aorta in E10.5 Phox2$\mathrm{B}^{\mathrm{LacZ} / \mathrm{LacZ}}$ embryos (Fig. 1D), indicating that Phox2B is directly or indirectly implicated in the upregulation of DLK1 in SA cells.

At more caudal regions, in the area of the developing adrenal cortex, identified by the expression of steroidogenic factor 1 (SF-1), a strong DLK1 signal matching the area of SF-1 expression was observed (Fig. 2 A,D). A stream of cells expressing Phox2B and Sox10, a marker for neural crest cells, glial cells, and early SA precursors, was identified in close proximity to the developing adrenal cortex (Fig. 2B and C). These cells most likely represent chromaffin cell precursors migrating to the adrenal Anlage. Interestingly, in the area of Phox2B/Sox10 expression only few cells were positive for DLK1. At this developmental stage and axial level not all SA precursors have undergone catecholaminergic differentiation as indicated by the greater number of Phox2B than $\mathrm{TH}$ immunoreactive cells in this region (Fig. 2E and F). DLK1-ISH in combination with either $\mathrm{TH}$ or Phox2B immunostaining revealed that TH-immunoreactive cell co-express DLK1, while only a subpopulation of Phox2B positive cells are positive for DLK1. This finding suggests that at least some of the more immature Phox2B positive/TH negative precursors lack DLK1 expression, indicating that DLK1 is upregulated during early SA cell differentiation most likely between the onset of Phox2B and TH expression.

At E11.5 TH-positive cells have invaded the adrenal gland. At this age DLK1-expression in the adrenal gland appears diffuse and only partially overlaps with $\mathrm{TH}$-immunoreactivity (Fig. 3A-C). The $\mathrm{OZ}$ at E11.5 was identified by the presence of TH-immmunoreactivity and Phox2B-expression and the absence of neurofilament-68 expression, which distinguishes it from prevertebral ganglia (Schober et al., 2013). A strong signal for DLK1 was detected in the area of the OZ (Fig. 3D-E).

In sympathetic ganglia from E11.5 onwards throughout embryonic development the expression of DLK1 is restricted to a small subpopulation of cells, while the majority of TH positive cells are negative for DLK1. In Fig. 4 DLK1 expression and TH-immunoreactivity in
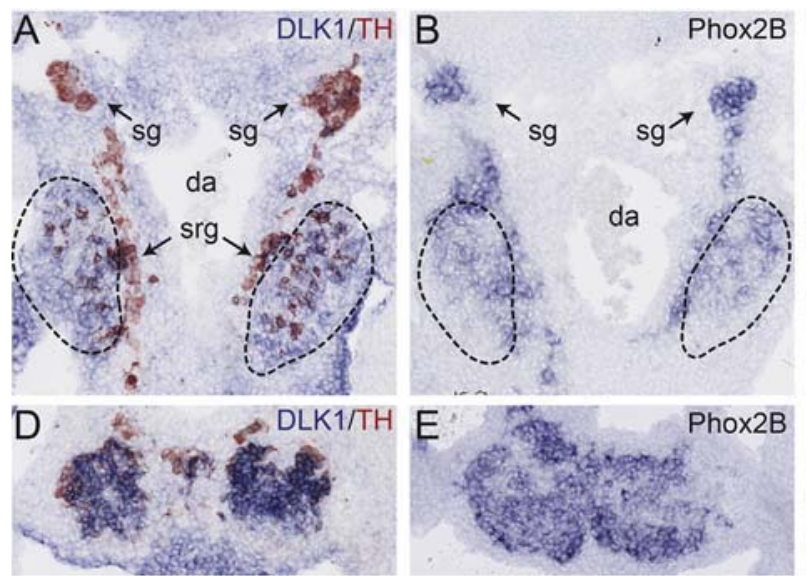

C
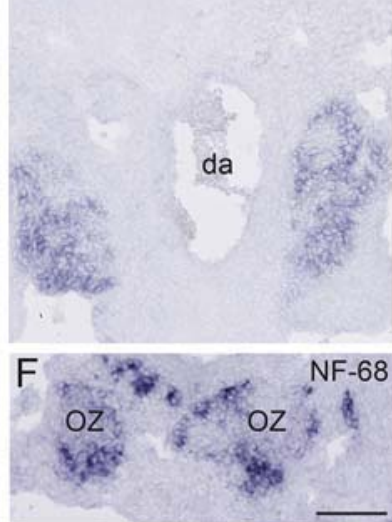

Fig. 3. Expression of DLK1 in (A) the adrenal gland and (D) the organ of Zuckerkandl at E11.5. Photomicrographs show cross sections of E11.5 mouse embryos at the level of the (A-C) adrenal gland and (D-F) the OZ. (A, D) In-situ-Hybridizations for DLK1 (blue) followed by immunostainings for TH (red) were carried out. Near adjacent sections were labelled with (B,E) Phox2B, (C) SF-1, a marker for the adrenal cortex, or (F) neurofilament-68. (da) dorsal aorta; (OZ) organ of Zuckerkandl; (sg) sympathetic ganglion; (srg) suprarenal ganglion; bar: $100 \mu \mathrm{m}$. 

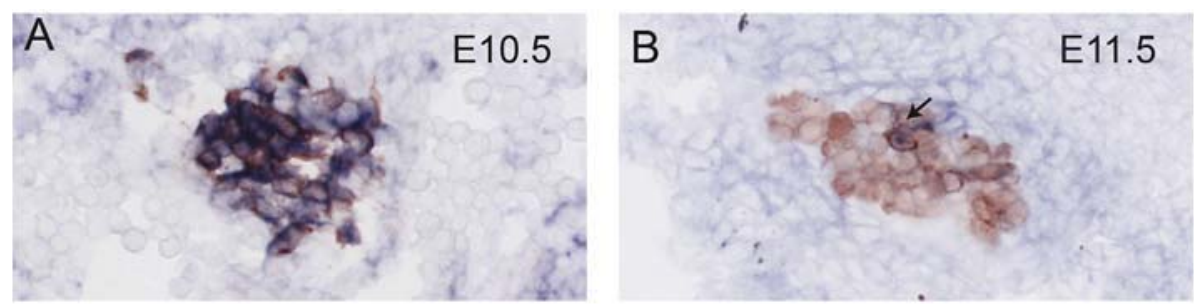

Fig. 4. Expression of DLK1 in thoracic sympathetic ganglia at E10.5, E11.5 E13.5 and E18.5. In-situ-hybridizations for DLK1 (blue) followed by immunostainings for $\mathrm{TH}$ (red cytoplasmatic stain) were carried out. Note that DLK1 expression is restricted to a subpopulation of TH-immunoreactive cells (arrows) from E11.5 onwards. Bar: $50 \mu \mathrm{m}$.
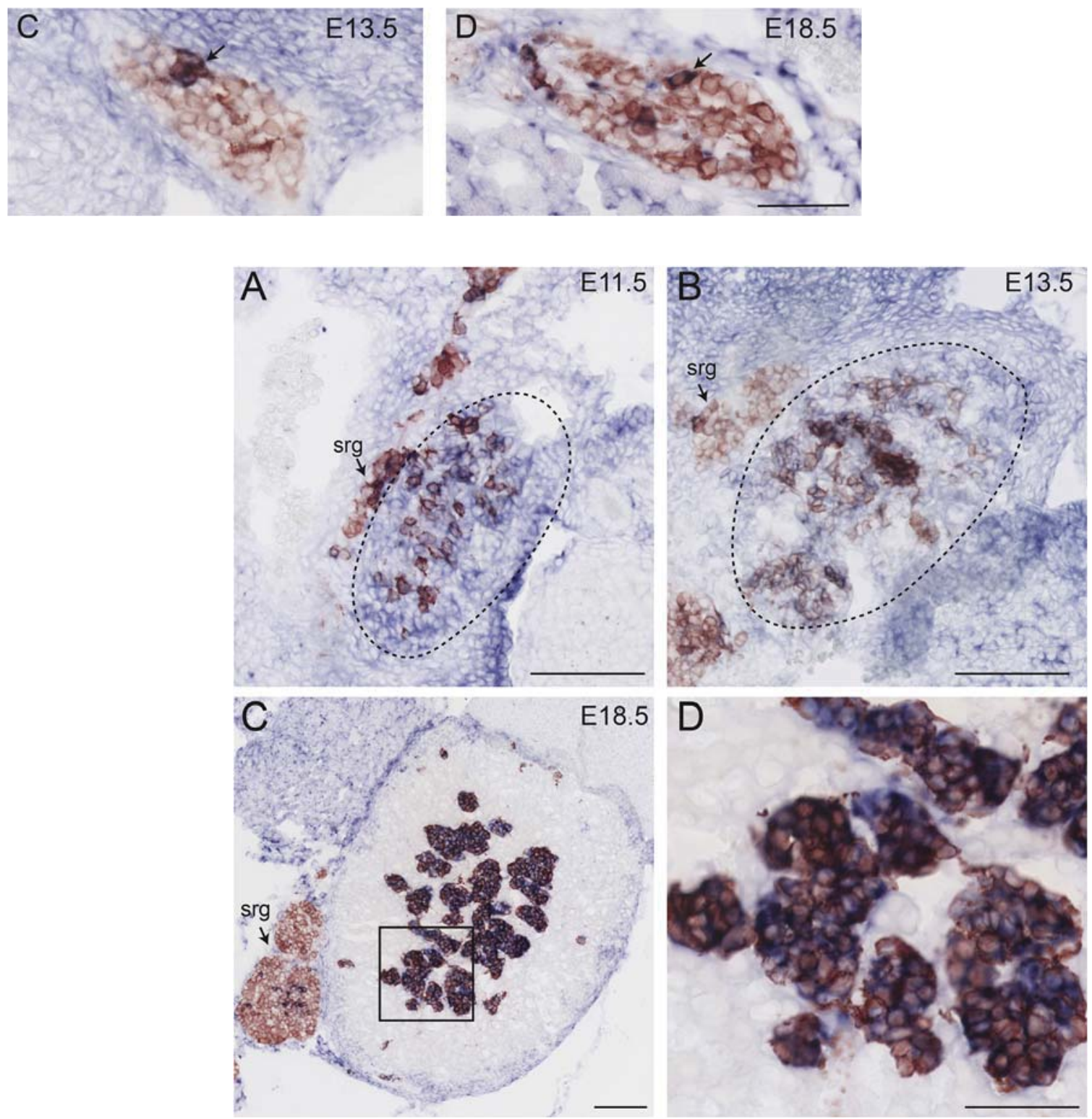

Fig. 5. Expression of DLK1 in the developing adrenal gland at (A) E11.5, (B) E13.5, and (C) E18.5. (D) higher magnification of inset in (C). In-situ-hybridizations for DLK1 (blue) followed by immunostainings for TH (red cytoplasmatic stain) were carried out. (srg) suprarenal ganglion; Bars: (A-C) $100 \mu$ m, (D) $50 \mu m$.

thoracic sympathetic ganglia of E10.5, E11.5, E13.5 and E18.5 mouse embryos are shown. A Similar staining pattern was observed in paravertebral sympathetic ganglia of other axial levels and in prevertebral ganglia like the suprarenal ganglion (Figs. 3A, Fig. 5A-C) and the celiac-superior mesenteric ganglion complex (not shown), with a slight temporal shift depending on the axial level. In contrast to this, in the adrenal gland the expression of DLK1 becomes progressively confined to chromaffin cells, with all TH-immunoreactive cells exhibiting a strong signal for DLK1 at E18.5 (Fig. 5). Moderate expression of DLK1 was also observed in the periphery of the adrenal cortex. Similarly, the TH-positive cells in the organ of Zuckerkandl maintain DLK1 expression throughout embryonic development (Fig. 6).

\section{Discussion}

We show that DLK1 is transiently expressed in early sympathetic neuron progenitors at E10.5. and that its expression is downstream of Phox2B. This suggests that DLK1 is upregulated in the course of early SA differentiation, which is essentially controlled by Phox2B. However, as Phox2B is required for all aspects of SA differentiation and initiates a large set of other transcription factors (Huber, 2006), the requirement of Phox2B may well be indirect. It has been reported that hypoxia 

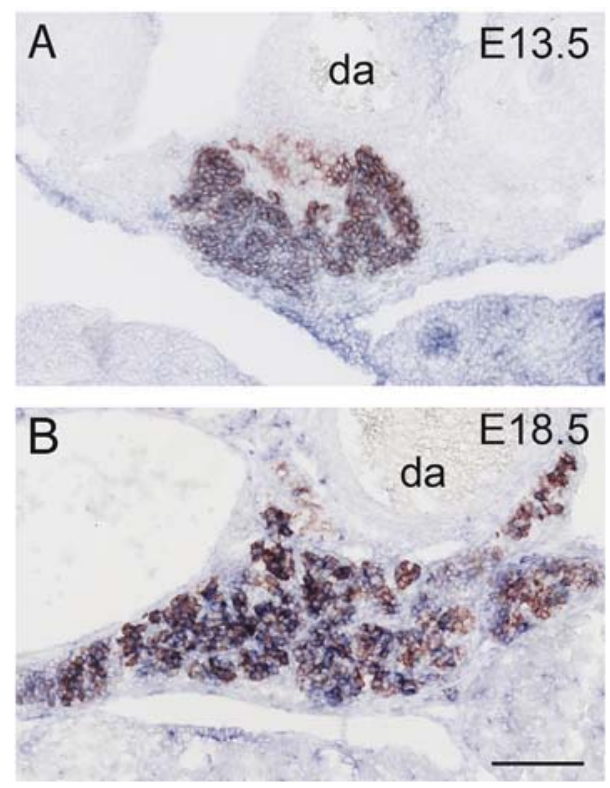

Fig. 6. Expression of DLK1 in the organ of Zuckerkandl at (A) E13.5 and (B) E18.5. In-situ-hybridizations for DLK1 (blue) followed by immunostainings for TH (red cytoplasmatic stain) were carried out. (da) dorsal aorta; bar: $100 \mu \mathrm{m}$.

upregulates DLK1 expression in neuroblastoma cells, mediated by hypoxia-inducible factors (HIFs) 1 and 2 (Kim et al., 2009). Interestingly, HIF-2a shows a similar spatiotemporal expression pattern in developing sympathetic ganglia as DLK1 and it is also absent in primary sympathetic ganglia of mice lacking Phox2B (El Faitwri, unpublished data).

From E11.5 onwards the expression of DLK1 mRNA is restricted to a small subpopulation of TH-positive cells in sympathetic ganglia, which may represent immature progenitor-like cells. This is conceivable, as neurogenesis from neural crest derived progenitors is going on for several days in sympathetic ganglia (Tsarovina et al., 2008). Alternatively, DLK1-expressing cells in sympathetic ganglia may represent small-intensively fluorescent cells, which resemble chromaffin cells (Eränkö, 1978). As shown here and by others, chromaffin cells, as well as some other endocrine cells, maintain DLK1 throughout prenatal and postnatal life (Jensen et al., 1993; Larsen et al., 1996). Together, this expression pattern suggests a role of DLK1 in early SA differentiation as well as in endocrine differentiation and/or function.

DLK1 is believed to exert its functions primarily during development and regeneration of various cells and tissues such as preadipocytes (Smas and Sul, 1993), the hematopoietic system (Li et al., 2005; Mirshekar-Syahkal et al., 2013) and the liver (Zhu et al., 2012). Furthermore, it plays an important role in tumor biology. In neuroblastoma high DLK1 expression was attributed to poorly differentiated cells and linked to increased tumor growth and tumorigenicity (Kim et al., 2009; Begum et al., 2012). Interestingly, another report associated high DLK1 expression in neuroblastoma with a cell type exhibiting traits of differentiated chromaffin cells (van Limpt et al., 2003). These contradictory findings, however, correlate well with the normal spatiotemporal expression pattern of DLK1, with high DLK1 expression in immature sympathetic neuron progenitors and chromaffin cells of later developmental stages.

The narrow time frame of DLK1 expression in sympathetic ganglia suggests a function during the early development of sympathetic neuron progenitors. Studies in neuroblastoma have suggested that DLK1 suppresses neuronal differentiation, inhibits neurite outgrowth, and promotes progenitor maintenance (Kim et al., 2009; Kim, 2010; Begum et al., 2012). Thus, possible roles of DLK1 in developing sympathetic ganglia may include the regulation of progenitor maintenance and the timing of differentiation.

\section{Acknowledgements}

We thank Ute Baur and Lydia Koschny for their excellent technical assistance. Tehani El Faitwri was supported by the Ministry of Higher Education, Libya.

\section{Appendix A. Supplementary data}

Supplementary data related to this article can be found

\section{References}

Anderson, D.J., Axel, R., 1986. A bipotential neuroendocrine precursor whose choice of cell fate is determined by NGF and glucocorticoids. Cell 47, 1079-1090.

Appelbe, O.K., Yevtodiyenko, A., Muniz-Talavera, H., Schmidt, J.V., 2013. Conditional deletions refine the embryonic requirement for Dlk1. Mech. Dev. 130, 143-159. https://doi.org/10.1016/j.mod.2012.09.010.

Begum, A., Kim, Y., Lin, Q., Yun, Z., 2012. DLK1, delta-like 1 homolog (Drosophila), regulates tumor cell differentiation in vivo. Canc. Lett. 318, 26-33. https://doi.org/ 10.1016/j.canlet.2011.11.032.

Bray, S.J., 2006. Notch signalling: a simple pathway becomes complex. Nat. Rev. Mol. Cell Biol. 7, 678-689. https://doi.org/10.1038/nrm2009.

Cai, C.-M., Xiao, X., Wu, B.-H., Wei, B.-F., Han, Z.-G., 2016. Targeting endogenous DLK1 exerts antitumor effect on hepatocellular carcinoma through initiating cell differentiation. Oncotarget 7, 71466-71476. https://doi.org/10.18632/oncotarget.12214.

Chan, W.H., Anderson, C.R., Gonsalvez, D.G., 2018. From proliferation to target innervation: signaling molecules that direct sympathetic nervous system development. Cell Tissue Res. 372, 171-193. https://doi.org/10.1007/s00441-017-2693-x.

D'Souza, B., Meloty-Kapella, L., Weinmaster, G., 2010. Canonical and non-canonical Notch ligands. Curr. Top. Dev. Biol. 92, 73-129. https://doi.org/10.1016/S00702153(10)92003-6.

Eränkö, O., 1978. Small intensely fluorescent (SIF) cells and nervous transmission in sympathetic ganglia. Annu. Rev. Pharmacol. Toxicol. 18, 417-430. https://doi.org/ 10.1146/annurev.pa.18.040178.002221.

Ernsberger, U., Patzke, H., Rohrer, H., 1997. The developmental expression of choline acetyltransferase (ChAT) and the neuropeptide VIP in chick sympathetic neurons: evidence for different regulatory events in cholinergic differentiation. Mech. Dev. 68, $115-126$.

Falix, F.A., Tjon-A-Loi, M.R.S., Gaemers, I.C., Aronson, D.C., Lamers, W.H., 2013. DLK1 protein expression during mouse development provides new insights into its function. ISRN Dev. Biol. 2013. https://doi.org/10.1155/2013/628962.

Fiúza, U.-M., Arias, A.M., 2007. Cell and molecular biology of Notch. J. Endocrinol. 194, 459-474. https://doi.org/10.1677/JOE-07-0242.

Furlan, A., Dyachuk, V., Kastriti, M.E., Calvo-Enrique, L., Abdo, H., Hadjab, S., Chontorotzea, T., Akkuratova, N., Usoskin, D., Kamenev, D., Petersen, J., Sunadome, K., Memic, F., Marklund, U., Fried, K., Topilko, P., Lallemend, F., Kharchenko, P.V., Ernfors, P., Adameyko, I., 2017. Multipotent peripheral glial cells generate neuroendocrine cells of the adrenal medulla. Science 357. https://doi.org/10.1126/ science.aal3753.

Gubina, E., Ruiz-Hidalgo, M.J., Baladrón, V., Laborda, J., 2000. Assignment of dlk (Dlk1) to mouse chromosome band 12E-F1 by in situ hybridization. Cytogenet. Cell Genet. 88, 322-323. https://doi.org/10.1159/000015519.

Gubina, E., Ruiz-Hidalgo, M.J., Baladrón, V., Laborda, J., 1999. Assignment of DLK1 to human chromosome band $14 \mathrm{q} 32$ by in situ hybridization. Cytogenet. Cell Genet. 84 , 206-207. https://doi.org/10.1159/000015259.

Gut, P., Huber, K., Lohr, J., Brühl, B., Oberle, S., Treier, M., Ernsberger, U., Kalcheim, C. Unsicker, K., 2005. Lack of an adrenal cortex in Sf1 mutant mice is compatible with the generation and differentiation of chromaffin cells. Development 132, 4611-4619. https://doi.org/10.1242/dev.02052.

Hedlund, G.P., Carlsson, H.E., Shieck, E., Nilsson, I., Lundblad, C., Arons, S., Iversen, A.K. Looman, C., Jensen, H.E., Hau, J., 2003. Fetal antigen 1 (FA1) in the adult rat adrenal gland, ovary and pituitary gland. In Vivo 17, 1-4.

Huber, K., 2015. Segregation of neuronal and neuroendocrine differentiation in the sympathoadrenal lineage. Cell Tissue Res. 359, 333-341. https://doi.org/10.1007/ s00441-014-1947-0.

Huber, K., 2006. The sympathoadrenal cell lineage: specification, diversification, and new perspectives. Dev. Biol. 298, 335-343. https://doi.org/10.1016/j.ydbio.2006.07. 010.

Huber, K., Brühl, B., Guillemot, F., Olson, E.N., Ernsberger, U., Unsicker, K., 2002. Development of chromaffin cells depends on MASH1 function. Development 129, 4729-4738.

Huber, K., Karch, N., Ernsberger, U., Goridis, C., Unsicker, K., 2005. The role of Phox2B in chromaffin cell development. Dev. Biol. 279, 501-508. https://doi.org/10.1016/j. ydbio.2005.01.007.

Jensen, C.H., Teisner, B., Højrup, P., Rasmussen, H.B., Madsen, O.D., Nielsen, B., Skjødt, K., 1993. Studies on the isolation, structural analysis and tissue localization of fetal antigen 1 and its relation to a human adrenal-specific cDNA, pG2. Hum. Reprod. 8 , 635-641.

Kim, Y., 2010. Effect of retinoic acid and delta-like 1 homologue (DLK1) on differentiation in neuroblastoma. Nutr. Res. Pract. 4, 276-282. https://doi.org/10.4162/nrp. 2010.4.4.276 
Kim, Y., Lin, Q., Zelterman, D., Yun, Z., 2009. Hypoxia-regulated delta-like 1 homologue enhances cancer cell stemness and tumorigenicity. Canc. Res. 69, 9271-9280. https://doi.org/10.1158/0008-5472.CAN-09-1605.

Larsen, J.B., Jensen, C.H., Schrøder, H.D., Teisner, B., Bjerre, P., Hagen, C., 1996. Fetal antigen 1 and growth hormone in pituitary somatotroph cells. Lancet 347, 191.

Lee, Y.L., Helman, L., Hoffman, T., Laborda, J., 1995. dlk, pG2 and Pref-1 mRNAs encode similar proteins belonging to the EGF-like superfamily. Identification of polymorphic variants of this RNA. Biochim. Biophys. Acta 1261, 223-232.

Li, L., Forman, S.J., Bhatia, R., 2005. Expression of DLK1 in hematopoietic cells results in inhibition of differentiation and proliferation. Oncogene $24,4472-4476$. https://doi. org/10.1038/sj.onc.1208637.

Mirshekar-Syahkal, B., Haak, E., Kimber, G.M., van Leusden, K., Harvey, K., O'Rourke, J., Laborda, J., Bauer, S.R., de Bruijn, M.F.T.R., Ferguson-Smith, A.C., Dzierzak, E., Ottersbach, K., 2013. Dlk1 is a negative regulator of emerging hematopoietic stem and progenitor cells. Haematologica 98, 163-171. https://doi.org/10.3324/ haematol.2012.070789.

Moon, Y.S., Smas, C.M., Lee, K., Villena, J.A., Kim, K.-H., Yun, E.J., Sul, H.S., 2002. Mice lacking paternally expressed pref-1/dlk1 display growth retardation and accelerated adiposity. Mol. Cell Biol. 22, 5585-5592. https://doi.org/10.1128/MCB.22.15.55855592.2002.

Pattyn, A., Guillemot, F., Brunet, J.-F., 2006. Delays in neuronal differentiation in Mash1/ Ascl1 mutants. Dev. Biol. 295, 67-75. https://doi.org/10.1016/j.ydbio.2006.03.008.

Pattyn, A., Morin, X., Cremer, H., Goridis, C., Brunet, J.F., 1999. The homeobox gene Phox $2 \mathrm{~b}$ is essential for the development of autonomic neural crest derivatives. Nature 399, 366-370. https://doi.org/10.1038/20700.

Pattyn, A., Morin, X., Cremer, H., Goridis, C., Brunet, J.F., 1997. Expression and interactions of the two closely related homeobox genes Phox2a and Phox2b during neurogenesis. Development 124, 4065-4075.

Schober, A., Parlato, R., Huber, K., Kinscherf, R., Hartleben, B., Huber, T.B., Schütz, G., Unsicker, K., 2013. Cell loss and autophagy in the extra-adrenal chromaffin organ of
Zuckerkandl are regulated by glucocorticoid signalling. J. Neuroendocrinol. 25, 34-47. https://doi.org/10.1111/j.1365-2826.2012.02367.x.

Smas, C.M., Green, D., Sul, H.S., 1994. Structural characterization and alternate splicing of the gene encoding the preadipocyte EGF-like protein pref-1. Biochemistry 33, 9257-9265.

Smas, C.M., Sul, H.S., 1993. Pref-1, a protein containing EGF-like repeats, inhibits adipocyte differentiation. Cell 73, 725-734.

Tsarovina, K., Schellenberger, J., Schneider, C., Rohrer, H., 2008. Progenitor cell maintenance and neurogenesis in sympathetic ganglia involves Notch signaling. Mol. Cell. Neurosci. 37, 20-31. https://doi.org/10.1016/j.mcn.2007.08.010.

Tsubota, S., Kadomatsu, K., 2018. Origin and initiation mechanisms of neuroblastoma. Cell Tissue Res. 372, 211-221. https://doi.org/10.1007/s00441-018-2796-z.

van Limpt, V.A.E., Chan, A.J., van Sluis, P.G., Caron, H.N., van Noesel, C.J.M., Versteeg, R., 2003. High delta-like 1 expression in a subset of neuroblastoma cell lines corresponds to a differentiated chromaffin cell type. Int. J. Canc. 105, 61-69. https://doi. org/10.1002/ijc.11047.

West, G.B., Shepherd, D.M., Hunter, R.B., Macgregor, A.R., 1953. The function of the organs of Zuckerkandl. Clin. Sci. 12, 317-325.

Xu, X., Liu, R.-F., Zhang, X., Huang, L.-Y., Chen, F., Fei, Q.-L., Han, Z.-G., 2012. DLK1 as a potential target against cancer stem/progenitor cells of hepatocellular carcinoma. Mol. Canc. Therapeut. 11, 629-638. https://doi.org/10.1158/1535-7163.MCT-11Mol. Canc.

Yin, D., Xie, D., Sakajiri, S., Miller, C.W., Zhu, H., Popoviciu, M.L., Said, J.W., Black, K.L., Koeffler, H.P., 2006. DLK1: increased expression in gliomas and associated with oncogenic activities. Oncogene 25, 1852-1861. https://doi.org/10.1038/sj.onc. 1209219.

Zhu, N.-L., Asahina, K., Wang, J., Ueno, A., Lazaro, R., Miyaoka, Y., Miyajima, A., Tsukamoto, H., 2012. Hepatic stellate cell-derived delta-like homolog 1 (DLK1) protein in liver regeneration. J. Biol. Chem. 287, 10355-10367. https://doi.org/10. 1074/jbc.M111.312751. 